\title{
Acupuncture and reflexology for patients undergoing chemotherapy: an observational study
}

\section{Suzanne Jane Grant ( $\nabla$ s.grant@westernsydney.edu.au )}

NICM Health Research Institute, Western Sydney University https://orcid.org/0000-0002-9491-203X

\section{Gretel Spiegel}

Chris O Brien Cancer Centre: Chris O'Brien Lifehouse

\section{Amanda BRAND}

Chris O Brien Cancer Centre: Chris O'Brien Lifehouse

\section{Ki Kyung KWON}

UWS NICM: Western Sydney University The National Institute of Complementary Medicine

\section{Gillian HELLER}

NHMRC Clinical Trials Centre

\section{Victoria $\mathrm{CHOI}$}

Chris O Brien Cancer Centre: Chris O'Brien Lifehouse

\section{Emma Wong}

Chris O Brien Cancer Centre: Chris O'Brien Lifehouse

\section{Lindley RANDLE}

Chris O Brien Cancer Centre: Chris O'Brien Lifehouse

Judith LACEY

Chris O Brien Cancer Centre: Chris O'Brien Lifehouse

\section{Research Article}

Keywords: Supportive Care, Acupuncture, Reflexology, Cancer, Chemotherapy, Symptom

Posted Date: November 5th, 2021

DOI: https://doi.org/10.21203/rs.3.rs-941637/v1

License: (c) (i) This work is licensed under a Creative Commons Attribution 4.0 International License.

Read Full License 


\section{Abstract \\ Purpose}

Around three quarters of individuals undergoing chemotherapy self-report multiple symptoms. There is clinical trial evidence of effectiveness for acupuncture for commonly experienced symptoms, and emerging evidence for reflexology, but little is known about the effects of these therapies on multiple symptoms when implemented in a real world setting during active chemotherapy treatment.

\section{Methods}

This was a single-arm observational study of participants receiving reflexology and/or acupuncture while attending chemotherapy. Participants received a 20 minute reflexology treatment or a 20 minute acupuncture treatment or a combination of both. Patient reported outcome measures were administered before and after the treatment using the Edmonton Symptom Assessment Scale (ESAS).

\section{Results}

During the study period, 330 unique participants with cancer received acupuncture and/or reflexology treatments. Participants had, on average, 5.3 symptoms each which they reported as moderate to severe $(\geq 4 / 10)$ using the ESAS at baseline. Following treatment, participants reported 3.2 symptoms as moderate to severe. The symptom change for all participant encounters receiving any therapy was statistically significant for all symptoms, and clinically significant (a reduction of more than 1 ) for all symptoms except financial distress, appetite and memory. Clinically significant levels of global distress (<3) were reduced in $72 \%$ of all participants receiving either therapy. No adverse events were recorded.

\section{Conclusions}

The results indicate that acupuncture and reflexology administered alongside chemotherapy may reduce patient reported symptom burden and patient global symptom related distress. Future research would include an active control group, and consider confounding factors such as chemotherapy stage and medication.

\section{Introduction}

Chemotherapy side effects impact quality of life, psychological wellbeing and may impact on capacity to tolerate a full dose of treatment. Around three quarters of individuals undergoing chemotherapy selfreport multiple symptoms the most frequent being fatigue, anxiety, nausea and bowel disturbances [13]. Complementary therapies are increasingly being incorporated into supportive cancer care to assist patients in managing these symptoms. 
Acupuncture is increasingly used globally for cancer symptoms and side effects. It is offered across all National Institutes of Health cancer centres, and incorporated in ASCO endorsed guidelines [10, 11]. Randomised controlled trials (RCT) have demonstrated benefit for anxiety, depression, insomnia, vasomotor symptoms and other symptoms experienced by patients undergoing chemotherapy [10]. Acupuncture has been shown to be safe, and may provide an option for patients.

Reflexology is a non-invasive, localised touch therapy that is an easily administered therapeutic treatment well suited to the setting of a chemotherapy day unit. Studies have shown benefit for anxiety, sleep, pain and quality of life $[15,20,21]$. Together, acupuncture and reflexology may also assist in managing chemotherapy induced peripheral neuropathy.

Symptoms experienced by patients undergoing chemotherapy often appear in clusters [23]. While there is evidence of the beneficial effects of acupuncture for individual symptom control in clinical trial settings, and emerging evidence for reflexology, little is known about the effects of reflexology and acupuncture and the treatment of multiple symptoms when implemented in a real world setting during chemotherapy treatment.

The aim of this study was to investigate if acupuncture and/or reflexology improved self-reported symptoms by patients undergoing chemotherapy.

\section{Methods}

This was a single-arm observational study of participants who utilised reflexology and/or acupuncture services while attending chemotherapy at the Chris O'Brien Lifehouse during the period of 2017 to 2020. The study received ethics approval from the Sydney Local Area Health District Ethics Committee in May 2019 (HREC/18/RPAH/519.

\section{Participants}

Patients receiving chemotherapy for solid tumours in the hospital day therapy unit were offered acupuncture or reflexology therapy. Participants could self-refer or be referred by healthcare professionals within the hospital. Treatments were provided free of charge to the patient, funded by a philanthropic grant to the hospital. Patients were excluded if they had profound neutropenia, thrombocytopenia (platelets $<50$ ), selected skin conditions or risk of bruising due to their coagulation status.

\section{Setting}

The Chris O'Brien Lifehouse in Australia, operates as a non-for-profit cancer hospital and services over 15,000 patients per year, and has a dedicated integrative oncology service [7]. The Day Therapy unit has over 45 chemotherapy chairs with 20,000 appointments annually. The acupuncture and reflexology service is available twice a week, over a 90 minute period in the chemotherapy suite with an acupuncturist and a reflexologist, or at times both of these. Patients were treated in either their chair while having their infusion or in a multi-chair room within the day therapy unit. 


\section{Intervention}

Participants received a 20 minute reflexology treatment or a 20 minute acupuncture treatment or, if requested and available, a combination of both. Where participants were undergoing an infusion through their arm that limb was typically not included in the acupuncture points selected. Acupuncture points were restricted to those that could be safely administered while the patient was seated. Therapists had a minimum of 5 years' experience working with cancer patients, and were credentialed to work within the hospital setting.

\section{Outcome measure}

Patient reported outcome measures were administered before and after the treatment using the Edmonton Symptom Assessment Scale (ESAS) [1]. The ESAS R includes nine symptoms rated on a visual analogue scale (VAS) from 0 to 10 . We used a modified ESAS-17 which includes the core items with eight additional items relevant to patients with cancer (sleep, wellbeing, spiritual pain, financial distress, hot flashes, numbness/tingling, dry mouth and memory). Participants completed the initial ESAS prior to treatment and were asked to select a value that related to how they felt in the last 24 hours. Immediately after treatment, they were asked to report on how they felt "right now". The ESAS has three subscales: the physical distress score (PHS), a composite of six symptoms - pain, fatigue, nausea, drowsiness, appetite and shortness of breath (0-60); the psychological stress score (PSS), a sum of depression and anxiety (0-20); and the global distress score (GDS) a sum of the PHS, PSS and well-being $(0-90)[8]$. The higher the score, the more distress.

The ESAS was administered by a research assistant not providing treatment to minimise administration bias. Basic demographic data, and primary cancer diagnosis were extracted from the electronic medical record.

\section{Statistical analysis}

Statistical analysis was conducted using the statistical software R version 4.0.2 [16]. Descriptive statistics were used to analyze demographic information. In order to correct for repeat treatments, generalized estimation equation methods were used to compute means, standard deviations, and tests for changes from baseline, for the ESAS symptom scores and composite scores.

Change of ESAS scores greater than 1 are considered clinically significant. For the physical, emotional and total symptom distress subscales, clinically significant reductions are as follows: PHS $\geq 2, P S S \geq 2$ and GDS $\geq 3$ [8]. Degree of symptom burden was classified by 0 as 'no burden', 1-3 'mild', 4-6 'moderate' and 7-10 'severe' burden. Moderate and severe burden were further classified as 'clinically significant' [18].

A separate analysis of the mean was calculated for the different therapy groups (acupuncture, reflexology, combined). Paired t-tests were used to determine the change in scores in mean and standard deviation. 


\section{Results}

During the study period, 330 unique participants with a cancer diagnosis received acupuncture and/or reflexology treatments while undergoing chemotherapy. Participants were mainly female (79\%) with breast cancer (31\%), and a median age of 56 (Table 1).

\section{Baseline presenting symptoms}

The most prevalent symptoms (ESAS $\geq 1$ ) of any therapy were poor sleep (85\%), fatigue (85\%) and decreased sense of well-being (95\%) (Table 1). Presenting symptoms were similar across acupuncture, reflexology and acupuncture/reflexology therapies. 
Table 1

Demographics and Baseline Presenting Symptoms ${ }^{1}$

\begin{tabular}{|c|c|c|c|c|c|}
\hline Characteristic & Overall & $\mathbf{N}$ & Acup & Reflex & Both \\
\hline & $N=330$ & & $N=72$ & $N=198$ & $N=60$ \\
\hline Age $(n=326)$ & $\begin{array}{l}56(43, \\
65)\end{array}$ & & $\begin{array}{l}55(41, \\
62)\end{array}$ & $\begin{array}{l}57(44, \\
67)\end{array}$ & $\begin{array}{l}55(45, \\
60)\end{array}$ \\
\hline Unknown & 4 & & 0 & 4 & 0 \\
\hline \multicolumn{6}{|l|}{ Gender $(n=293)$} \\
\hline $\mathrm{F}$ & $\begin{array}{l}231 \\
(79 \%)\end{array}$ & & 49 (75\%) & $\begin{array}{l}141 \\
(82 \%)\end{array}$ & 41 (75\%) \\
\hline M & $62(21 \%)$ & & $16(25 \%)$ & $32(18 \%)$ & $14(25 \%)$ \\
\hline Unknown/Not stated & 37 & & 7 & 25 & 5 \\
\hline \multicolumn{6}{|l|}{ Diagnosis $(n=330)$} \\
\hline Breast & $\begin{array}{l}100 \\
(31 \%)\end{array}$ & & $26(37 \%)$ & $58(30 \%)$ & $16(28 \%)$ \\
\hline Colorectal & $\begin{array}{l}30 \\
(9.3 \%)\end{array}$ & & $12(17 \%)$ & $\begin{array}{l}12 \\
(6.2 \%)\end{array}$ & $6(11 \%)$ \\
\hline Gynaecological & $55(17 \%)$ & & $9(13 \%)$ & $38(19 \%)$ & $8(14 \%)$ \\
\hline Head and Neck & $\begin{array}{l}21 \\
(6.5 \%)\end{array}$ & & $3(4.2 \%)$ & $\begin{array}{l}15 \\
(7.7 \%)\end{array}$ & $3(5.3 \%)$ \\
\hline Lung & $\begin{array}{l}32 \\
(9.9 \%)\end{array}$ & & $2(2.8 \%)$ & $22(11 \%)$ & $8(14 \%)$ \\
\hline $\begin{array}{l}\text { Other: Skin, Brain, Prostate, Pancreatic, } \\
\text { Sarcoma }\end{array}$ & $73(23 \%)$ & & $13(18 \%)$ & $46(24 \%)$ & $14(25 \%)$ \\
\hline Other & $19(9 \%)$ & & $7(10 \%)$ & $7(4 \%)$ & $5(8 \%)$ \\
\hline Baseline presenting symptoms ${ }^{2}$ & & $\mathrm{~N}$ & & & \\
\hline Fatigue & $\begin{array}{l}279 \\
(85 \%)\end{array}$ & 330 & $60(83 \%)$ & $\begin{array}{l}170 \\
(86 \%)\end{array}$ & 49 (82\%) \\
\hline Sleep & $\begin{array}{l}278 \\
(85 \%)\end{array}$ & 328 & 60 (83\%) & $\begin{array}{l}168 \\
(86 \%)\end{array}$ & $50(83 \%)$ \\
\hline Memory & $\begin{array}{l}235 \\
(73 \%)\end{array}$ & 324 & 48 (67\%) & $\begin{array}{l}140 \\
(72 \%)\end{array}$ & 47 (81\%) \\
\hline
\end{tabular}

${ }^{1}$ Missing data: due to a changeover in electronic medical record systems within the hospital not all demographics were able to be extracted. ${ }^{2}$ Where participants scored the symptom $\geq 1$ 


\begin{tabular}{|c|c|c|c|c|c|}
\hline Characteristic & Overall & $\mathbf{N}$ & Acup & Reflex & Both \\
\hline Appetite & $\begin{array}{l}231 \\
(71 \%)\end{array}$ & 327 & 48 (68\%) & $\begin{array}{l}139 \\
(71 \%)\end{array}$ & $44(73 \%)$ \\
\hline PSS & $\begin{array}{l}212 \\
(65 \%)\end{array}$ & 326 & $45(64 \%)$ & $\begin{array}{l}136 \\
(69 \%)\end{array}$ & $31(52 \%)$ \\
\hline Drowsiness & $\begin{array}{l}210 \\
(64 \%)\end{array}$ & 328 & $41(57 \%)$ & $\begin{array}{l}129 \\
(66 \%)\end{array}$ & $40(67 \%)$ \\
\hline Pain & $\begin{array}{l}199 \\
(60 \%)\end{array}$ & 329 & $44(61 \%)$ & $\begin{array}{l}117 \\
(59 \%)\end{array}$ & 38 (63\%) \\
\hline Anxiety & $\begin{array}{l}198 \\
(60 \%)\end{array}$ & 329 & $41(58 \%)$ & $\begin{array}{l}129 \\
(65 \%)\end{array}$ & $28(47 \%)$ \\
\hline Dry mouth & $\begin{array}{l}197 \\
(60 \%)\end{array}$ & 326 & $44(61 \%)$ & $\begin{array}{l}116 \\
(59 \%)\end{array}$ & 37 (64\%) \\
\hline Numbness & $\begin{array}{l}177 \\
(55 \%)\end{array}$ & 324 & $42(58 \%)$ & $\begin{array}{l}103 \\
(53 \%)\end{array}$ & $32(56 \%)$ \\
\hline Financial distress & $\begin{array}{l}170 \\
(52 \%)\end{array}$ & 325 & $40(56 \%)$ & $99(51 \%)$ & $31(52 \%)$ \\
\hline Depression & $\begin{array}{l}166 \\
(51 \%)\end{array}$ & 327 & $36(51 \%)$ & $\begin{array}{l}104 \\
(53 \%)\end{array}$ & $26(43 \%)$ \\
\hline Shortness of breath & $\begin{array}{l}152 \\
(46 \%)\end{array}$ & 330 & $36(50 \%)$ & $91(46 \%)$ & $25(42 \%)$ \\
\hline Hot flashes & $\begin{array}{l}130 \\
(40 \%)\end{array}$ & 325 & $29(40 \%)$ & 77 (39\%) & $24(42 \%)$ \\
\hline Nausea & $\begin{array}{l}129 \\
(39 \%)\end{array}$ & 329 & $26(36 \%)$ & $78(40 \%)$ & $25(42 \%)$ \\
\hline Spiritual pain & $\begin{array}{l}120 \\
(37 \%)\end{array}$ & 321 & $29(41 \%)$ & $69(36 \%)$ & $22(37 \%)$ \\
\hline
\end{tabular}

\section{Symptom change in all encounters}

For 330 participants, there were 809 encounters, with participants receiving an average of 2.45 (range 128) treatments each.

The symptom change for all participant encounters receiving any therapy was statistically significant for all symptoms. and clinically significant (a reduction of more than 1 ) for all symptoms except financial distress, appetite and memory (Table 2). 
Clinically significant changes were noted in overall global (GDS), physical symptom distress (PHS) and psychological stress score (PSS).

Table 2

Symptom change in all participant encounters ${ }^{1}$

\begin{tabular}{|c|c|c|c|c|c|c|c|c|}
\hline \multirow[b]{2}{*}{ ESAS Symptom } & \multicolumn{2}{|c|}{ All Encounters } & \multicolumn{2}{|c|}{ Acupuncture } & \multicolumn{2}{|c|}{ Reflexology } & \multicolumn{2}{|c|}{$\begin{array}{l}\text { Acupuncture + } \\
\text { Reflexology }\end{array}$} \\
\hline & $\mathrm{n}$ & $\begin{array}{l}\text { Mean } \\
\text { change }\end{array}$ & $\mathrm{n}$ & $\begin{array}{l}\text { Mean } \\
\text { change* }\end{array}$ & $\mathrm{n}$ & $\begin{array}{l}\text { Mean } \\
\text { change }\end{array}$ & $\mathrm{n}$ & Mean change \\
\hline Pain & 545 & 1.62 & 101 & 1.28 & 297 & 1.61 & 144 & 1.45 \\
\hline Fatigue & 670 & 1.83 & 128 & 1.88 & 385 & 1.72 & 155 & 2.01 \\
\hline Nausea & 316 & 1.59 & 61 & 1.80 & 173 & 1.55 & 82 & 1.48 \\
\hline Depression & 397 & 1.23 & 74 & 1.39 & 226 & 1.12 & 96 & 1.38 \\
\hline Anxiety & 492 & 1.76 & 86 & 1.49 & 289 & 1.72 & 116 & 1.74 \\
\hline Drowsiness & 513 & 1.24 & 93 & 1.35 & 292 & 1.18 & 127 & 1.17 \\
\hline $\begin{array}{l}\text { Shortness of } \\
\text { breath }\end{array}$ & 368 & 1.73 & 75 & 1.91 & 190 & 1.53 & 102 & 1.75 \\
\hline Appetite & 576 & 0.75 & 103 & 0.45 & 321 & 0.77 & 149 & 0.9 \\
\hline Sleep & 707 & 1.02 & 133 & 0.87 & 398 & 1.04 & 173 & 1.12 \\
\hline Wellbeing & 705 & 1.58 & 134 & 1.44 & 398 & 1.56 & 170 & 1.49 \\
\hline Financial distress & 414 & 0.74 & 93 & 0.99 & 229 & 0.6 & 90 & 0.81 \\
\hline Spiritual pain & 293 & 1.30 & 67 & 1.62 & 167 & 1.13 & 59 & 1.46 \\
\hline Hot flashes & 381 & 1.94 & 77 & 1.86 & 211 & 1.93 & 93 & 2.14 \\
\hline Dry mouth & 505 & 1.42 & 98 & 1.37 & 277 & 1.4 & 128 & 1.36 \\
\hline Numbness & 485 & 1.57 & 95 & 1.49 & 261 & 1.69 & 127 & 1.36 \\
\hline Memory & 634 & 0.96 & 115 & 1.00 & 354 & 0.9 & 162 & 0.97 \\
\hline GDS & 761 & 8.01 & 141 & 7.31 & 427 & 7.83 & 190 & 8.36 \\
\hline PHS & 756 & 5.15 & 143 & 4.87 & 425 & 4.89 & 185 & 5.68 \\
\hline PSS & 522 & 2.44 & 95 & 2.15 & 303 & 2.41 & 123 & 2.3 \\
\hline
\end{tabular}


Statistically significant and clinically significant changes were experienced for all symptoms with the exception of financial distress and appetite. There was a clinically and statistically significant mean change $(p<0.001)$ on all global distress $(-7.31)$, physical distress $(-4.87)$ and psychological symptom scores (-2.15).

\section{Reflexology group}

Statistically significant changes were found for all reported symptoms, and these changes were clinically significant with the exception of financial distress and appetite. There was a clinically and statistically significant change on all global distress (-7.83), physical distress (-4.89) and psychological (-2.41) symptom scores.

\section{Combined acupuncture and reflexology}

Combined treatment resulted in statistically and clinically significant changes for all symptoms with the exception of financial distress and memory. There was a clinically and statistically significant change on all global distress (-8.36), physical distress $(-5.68)$ and psychological symptom scores $(-2.3)$. There was no significant difference in mean changes between groups (acupuncture alone, reflexology alone, both therapies).

For the ESAS sub-scales, there were clinically and statistically significant mean changes for the global distress score (-8.01), the physical (-5.15) and the emotional distress score (-2.44).

Symptom severity. Moderate to severe $(\geq 4)$ symptoms at baseline were reported for fatigue ( $51 \%)$, poor sleep (51\%), and poor well-being (49\%) (Supplemental File: Table S1). After treatment, those reporting moderate to severe symptoms reduced in fatigue $(23 \%)$, poor sleep $(31 \%)$, and poor wellbeing $(22 \%)$.

Number of symptoms: Participants had, on average, 5.3 moderate to severe $(\geq 4 / 10)$ symptoms before treatment (Supplementary File: Table S1). Following treatment, participants reported 3.2 symptoms as moderate to severe.

\section{Clinical response rates}

Clinical response rates, defined in the methods, were highest for fatigue (63\%) and well-being (61\%) (Table 3). Pain (46\%) and anxiety (43\%) improvements were also experienced with a slightly higher response for pain in the reflexology group (49\%v44\%) and anxiety in the acupuncture group (49\%vs $43 \%)$. 
Table 3

Clinical Response Rates for Participants ${ }^{1}$

\begin{tabular}{|llllll|}
\hline Characteristic & Overall & $\mathbf{N}$ & Acu & Both & Reflex \\
\cline { 2 - 2 } & $\mathbf{N = 3 3 0}$ & & $\mathbf{N = 6 4}$ & $\mathbf{N}=66$ & $\mathbf{N}=200$ \\
\hline Fatigue & $205(63 \%)$ & 325 & $44(70 \%)$ & $41(64 \%)$ & $120(61 \%)$ \\
\hline Wellbeing & $191(61 \%)$ & 313 & $36(58 \%)$ & $41(64 \%)$ & $114(61 \%)$ \\
\hline Pain & $149(46 \%)$ & 326 & $27(44 \%)$ & $24(37 \%)$ & $98(49 \%)$ \\
\hline Anxiety & $140(43 \%)$ & 326 & $31(49 \%)$ & $24(37 \%)$ & $85(43 \%)$ \\
\hline Sleep & $121(41 \%)$ & 297 & $26(46 \%)$ & $27(44 \%)$ & $68(38 \%)$ \\
\hline Numbness & $123(39 \%)$ & 319 & $29(47 \%)$ & $23(37 \%)$ & $71(37 \%)$ \\
\hline Memory & $121(39 \%)$ & 314 & $28(45 \%)$ & $28(44 \%)$ & $65(34 \%)$ \\
\hline Drowsiness & $120(37 \%)$ & 325 & $24(38 \%)$ & $24(38 \%)$ & $72(36 \%)$ \\
\hline Dry mouth & $119(37 \%)$ & 318 & $21(34 \%)$ & $28(44 \%)$ & $70(36 \%)$ \\
\hline Appetite & $109(34 \%)$ & 322 & $15(24 \%)$ & $29(45 \%)$ & $65(33 \%)$ \\
\hline Depression & $97(30 \%)$ & 324 & $22(35 \%)$ & $14(22 \%)$ & $61(31 \%)$ \\
\hline Shortness of breath & $97(30 \%)$ & 327 & $20(32 \%)$ & $22(34 \%)$ & $55(28 \%)$ \\
\hline Nausea & $94(29 \%)$ & 325 & $20(32 \%)$ & $22(34 \%)$ & $52(26 \%)$ \\
\hline Hot flashes & $186(59 \%)$ & 316 & $37(61 \%)$ & $36(58 \%)$ & $113(59 \%)$ \\
\hline Financial distress & $70(22 \%)$ & 317 & $23(38 \%)$ & $14(22 \%)$ & $33(17 \%)$ \\
\hline Spiritual pain & $69(22 \%)$ & 309 & $19(34 \%)$ & $12(19 \%)$ & $38(20 \%)$ \\
\hline GDS & $215(72 \%)$ & 299 & $43(73 \%)$ & $38(62 \%)$ & $134(75 \%)$ \\
\hline PHS & $121 \%)$ & 324 & $29(47 \%)$ & $19(29 \%)$ & $73(37 \%)$ \\
\hline PSS & 315 & $18(30 \%)$ & $23(37 \%)$ & $50(26 \%)$ \\
\hline
\end{tabular}

${ }^{1}$ Clinical response rate: a 1-point decrease or more on ESAS individual symptoms; 2-point decrease or more on the ESAS PSS; 3-point decrease or more on the ESAS PHS and GDS.

Reduced fatigue was reported by $70 \%$ of patients in the acupuncture group, and $61 \%$ of the reflexology group. However, differences between groups were not statistically different. Global distress was improved in $72 \%$ of all patients receiving any therapy or combination of therapy.

No adverse events were reported. 


\section{Discussion}

This is one of the first observational studies to examine the effects of acupuncture and reflexology on patient reported symptom burden while undergoing chemotherapy in a routine care setting. Overall, patients receiving either or both therapies were likely to experience a clinically significant change in all symptoms except appetite, financial distress and memory. Clinically significant reductions in global distress (a reduction of more than 3 points) was reported in $72 \%$ of all participants using any therapy, with a mean reduction of 8 on the 90-point scale. There was no statistically significant difference between the responses to the therapies participants were given.

The most prevalent symptoms in our study for those presenting for acupuncture were sleep disturbance, fatigue and reduced appetite, and are consistent with frequently reported symptoms in other studies of cancer patients using acupuncture in a hospital setting $[6,9]$.

To date most studies directed at reducing the symptom burden of patients undergoing chemotherapy, have focused on self-help, nurse-led intervention, psychoeducation and cognitive behavioural therapies with mixed results $[3,5,22]$. Other non-pharmacological approaches specifically for symptom clusters in patients undergoing chemotherapy have included self-acupressure, and guided imagery [2].

Our study indicates that the use of reflexology for reducing the symptom burden of patients during chemotherapy may provide benefit. This is consistent with other studies, however, evidence limitations include small sample size and quasi-experimental designs [20].

Several studies have investigated acupuncture and reflexology specifically for a single symptom such as nausea and/or vomiting but few on the use of either acupuncture or reflexology for the reduction of several symptoms during chemotherapy $[4,12,17,19]$. Reflexology and acupuncture may be an option for patient to address multiple symptoms or symptom clusters with the flexibility to address changes over the course of treatment[14].

\section{Limitations}

This study was undertaken at a single cancer centre and may not be generalizable to other settings. Without a control group it is difficult to predict the placebo effect or the effect of simply being in a quiet, reclining environment for 20 minutes. This study did not control patient interaction with other staff, patients or friends during intervention and more accurately reflects real world practice.

We did not control for supportive care medications and this may have impacted on self-report symptoms. We also cannot eliminate selection bias. Participants were free to choose if they were interested in the intervention, and which intervention they preferred.

Although the service was initially offered only for 90 minutes one day a week, we expanded to two days and these days remained fixed. The reflexology service was available more frequently than the 
acupuncture.

Future research would include an active control group, factor in statistical measures for selection bias and consider confounding factors such as chemotherapy stage and medication. Research may also consider quality of life following chemotherapy, impact on dose delays, dose reductions, and reduced relative dose intensity (RDI) rates, and medication rates.

\section{Conclusion}

Acupuncture and reflexology can safely be administered alongside chemotherapy in the chemotherapy chair/suite to produce a clinically significant reduction in patient global symptom distress, physical and psychological distress and reported symptom burden. The results of the current study support the importance of advancing the investigation of acupuncture and reflexology for the management of individual symptoms and symptom clusters that occur within the context of cancer treatments.

\section{Declarations}

\section{Funding}

This research was supported by a donation from the McNiven family and Mostyn family. The funders had no role in study design, data collection and analysis, decision to publish, or preparation of the manuscript.

\section{Conflicts of interest/Competing interests}

None

\section{Availability of data and material}

Deidentified data set

\section{Code availability}

Not applicable

\section{Authors' contributions}

SG and GS conceived the study. SG, GS, JL and LR designed the study. SG, GS, VC, EW, KK and AB contributed to the data, data collection and cleaning. $\mathrm{GH}$ and SG performed the analysis. All members contributed to writing the final paper.

\section{Ethics approval}


The study received ethics approval from the Sydney Local Area Health District Ethics Committee in May 2019 (HREC/18/RPAH/519.

\section{Consent to participate}

Consent to participate as per Ethics approval.

\section{Consent for publication}

Not applicable

\section{References}

1. Chang VT, Hwang SS, Feuerman M (2000) Validation of the Edmonton symptom assessment scale Cancer: Interdisciplinary International Journal of the American Cancer Society 88: 2164-2171

2. Charalambous A, Giannakopoulou M, Bozas E, Marcou Y, Kitsios P, Paikousis L (2016) Guided imagery and progressive muscle relaxation as a cluster of symptoms management intervention in patients receiving chemotherapy: a randomized control trial PloS one 11: e0156911

3. Coolbrandt A, Wildiers H, Aertgeerts B, Van der Elst E, Laenen A, Dierckx de Casterlé B, van Achterberg T, Milisen K (2014) Characteristics and effectiveness of complex nursing interventions aimed at reducing symptom burden in adult patients treated with chemotherapy: a systematic review of randomized controlled trials Int J Nurs Stud 51: 495-510

4. Dikmen HA, Terzioglu FJPMN (2019) Effects of reflexology and progressive muscle relaxation on pain, fatigue, and quality of life during chemotherapy in gynecologic cancer patients 20: 47-53

5. Given C, Given B, Rahbar M, Jeon S, McCorkle R, Cimprich B, Galecki A, Kozachik S, Brady A, Fisher-Malloy MJ, Courtney K, Bowie E (2004) Effect of a Cognitive Behavioral Intervention on Reducing Symptom Severity During Chemotherapy Journal of Clinical Oncology 22: 507-516

6. Grant S, Kwon K, Naehrig D, Asher R, Lacey J (2021) Characteristics and Symptom Burden of Patients Accessing Acupuncture Services at a Cancer Hospital Integrative cancer therapies 20: 153473542110022

7. Grant SJ, Marthick M, Lacey J (2018) Establishing an integrative oncology service in the Australian healthcare setting-the Chris O'Brien Lifehouse Hospital experience Supportive Care in Cancer: $1-8$

8. Hui D, Shamieh O, Paiva CE, Khamash O, Perez-Cruz PE, Kwon JH, Muckaden MA, Park M, Arthur J, Bruera E (2016) Minimal clinically important difference in the physical, emotional, and total symptom distress scores of the Edmonton Symptom Assessment System Journal of pain symptom management 51: $262-269$ 
9. Lopez G, Garcia MK, Liu W, Spano M, Underwood S, Dibaj SS, Li Y, Moguel R, Williams J, Bruera E, Cohen L (2018) Outpatient acupuncture effects on patient self-reported symptoms in oncology care: a retrospective analysis Journal of Cancer 9: 3613-3619

10. Lyman GH, Greenlee H, Bohlke K, Bao T, DeMichele AM, Deng GE, Fouladbakhsh JM, Gil B, Hershman DL, Mansfield S (2018) Integrative Therapies During and After Breast Cancer Treatment: ASCO Endorsement of the SIO Clinical Practice Guideline Journal of Clinical Oncology 36(25):2647-2655

11. NCCN (2017) Antiemesis (Version 2.2017).. Accessed February 6, 2014. In: Editor (ed)^(eds) Book Antiemesis (Version 2.2017).. Accessed February 6, 2014., City.

12. Özdelikara A, Tan M (2017) The effect of reflexology on chemotherapy-induced nausea, vomiting, and fatigue in breast cancer patients Asia-Pacific journal of oncology nursing 4: 241

13. Pearce A, Haas M, Viney R, Pearson SA, Haywood P, Brown C, Ward R (2017) Incidence and severity of self-reported chemotherapy side effects in routine care: A prospective cohort study PloS one 12: e0184360

14. Price S, Long AF, Godfrey M (2013) Exploring the Needs and Concerns of Women with Early Breast Cancer during Chemotherapy: Valued Outcomes during a Course of Traditional Acupuncture Evidence-Based Complementary and Alternative Medicine 2013: 165891

15. Quattrin R, Zanini A, Buchini S, Turello D, Annunziata MA, Vidotti C, Colombatti A, Brusaferro S (2006) Use of reflexology foot massage to reduce anxiety in hospitalized cancer patients in chemotherapy treatment: methodology and outcomes Journal of nursing management 14: 96-105

16. R Core Team (2020) R: A language and environment for statistical computing. In: Editor (ed)^(eds) Book R: A language and environment for statistical computing. R Foundation for Statistical Computing, City.

17. Rithirangsriroj K, Manchana T, Akkayagorn L (2015) Efficacy of acupuncture in prevention of delayed chemotherapy induced nausea and vomiting in gynecologic cancer patients Gynecologic Oncology 136: 82-86

18. Selby D, Chakraborty A, Myers J, Saskin R, Mazzotta P, Gill A (2011) High Scores on the Edmonton Symptom Assessment Scale Identify Patients with Self-Defined High Symptom Burden Journal of Palliative Medicine 14: 1309-1316

19. Tas D, Uncu D, Sendur M, Koca N, Zengin N (2014) Acupuncture as a Complementary Treatment for Cancer Patients Receiving Chemotherapy Asian Pacific Journal of Cancer Prevention 15: 3139-3144

20. Wanchai A, Armer JM (2020) A systematic review association of reflexology in managing symptoms and side effects of breast cancer treatment Complementary Therapies in Clinical Practice 38 : 101074

Page 14/16 
21. Wyatt G, Sikorskii A, Rahbar MH, Victorson D, You M (2012) Health-Related Quality-of-Life Outcomes: A Reflexology Trial With Patients With Advanced-Stage Breast Cancer Oncology nursing forum 39: 568-577

22. Xiao W, Chow KM, So WK, Leung DY, Chan CW (2016) The effectiveness of psychoeducational intervention on managing symptom clusters in patients with cancer: A systematic review of randomized controlled trials Cancer Nursing 39: 279-291

23. Zia FZ, Olaku O, Bao T, Berger A, Deng G, Yin Fan A, Garcia MK, Herman PM, Kaptchuk TJ, Ladas EJ, Langevin HM, Lao L, Lu W, Napadow V, Niemtzow RC, Vickers AJ, Shelley Wang X, Witt CM, Mao JJ (2017) The National Cancer Institute's Conference on Acupuncture for Symptom Management in Oncology: State of the Science, Evidence, and Research Gaps J Natl Cancer Inst Monogr 2017

\section{Supplementary Tables}


Table S1

Symptom severity of participants ${ }^{1}$

\begin{tabular}{|lcccccccc|}
\hline & Pre & & & \multicolumn{7}{c}{ Post } \\
\hline Symptom & none & mild & mod & severe & none & mild & mod & severe \\
\hline Anxiety & 120 & 90 & 56 & 29 & 153 & 70 & 29 & 6 \\
\hline Appetite & 89 & 86 & 88 & 32 & 96 & 85 & 58 & 19 \\
\hline Depression & 144 & 98 & 38 & 15 & 170 & 60 & 24 & 4 \\
\hline Drowsiness & 109 & 84 & 64 & 38 & 113 & 85 & 45 & 15 \\
\hline Dry mouth & 118 & 85 & 60 & 32 & 133 & 82 & 31 & 12 \\
\hline Fatigue & 46 & 82 & 108 & 59 & 86 & 97 & 61 & 14 \\
\hline Financial distress & 137 & 79 & 43 & 36 & 144 & 69 & 27 & 18 \\
\hline Hot flashes & 171 & 55 & 45 & 24 & 181 & 46 & 19 & 12 \\
\hline Memory & 80 & 86 & 94 & 35 & 89 & 79 & 77 & 13 \\
\hline Nausea & 184 & 66 & 32 & 13 & 183 & 55 & 16 & 4 \\
\hline Numbness & 135 & 60 & 55 & 45 & 127 & 74 & 41 & 16 \\
\hline Pain & 114 & 90 & 60 & 31 & 135 & 85 & 31 & 7 \\
\hline Shortness of breath & 159 & 80 & 36 & 20 & 187 & 54 & 12 & 5 \\
\hline Sleep & 43 & 83 & 98 & 71 & 63 & 94 & 66 & 35 \\
\hline Spiritual pain & 183 & 61 & 39 & 12 & 193 & 47 & 15 & 3 \\
\hline Wellbeing & 31 & 103 & 114 & 47 & 77 & 110 & 56 & 15 \\
\hline Average number of symptoms per patient & & & & & & \\
\hline & 6.3 & 4.4 & 3.5 & 1.8 & 8.3 & 4.6 & 2.4 & 0.8 \\
\hline 'Degree of symptom burden was classified by 0 as 'no burden', $1-3$ 'mild', $4-6$ 'moderate' and $7-10$ \\
\hline severe' burden. Moderate and severe burden were further classified as 'clinically significant' \\
\hline
\end{tabular}

